\title{
Effect of Kindness-Based Meditation on Health and Well-Being: A Systematic Review and Meta-Analysis
}

Article in Journal of Consulting and Clinical Psychology · June 2014

DOI: $10.1037 / \mathrm{a} 0037249 \cdot$ Source: PubMed

CITATIONS

87
READS

1,352

4 authors, including:

\section{John Gallacher}

University of Oxford

224 PUBLICATIONS 11,063 CITATIONS

SEE PROFILE

Some of the authors of this publication are also working on these related projects:

Mindful Student Study: A randomised controlled trial of the provision of a mindfulness intervention to support university students' wellbeing and resilience to stress View project 


\title{
APA copyright notice: This article may not exactly replicate the final version published in the APA journal. It is not the copy of record. http://www.apa.org/pubs/journals/ccp
}

\section{Effect of Kindness-Based Meditation on Health and Wellbeing: A Systematic Review and Meta-Analysis}

\author{
Julieta Galante $^{1}$, Ignacio Galante ${ }^{2}$, Marie-Jet Bekkers ${ }^{3}$, John Gallacher ${ }^{1}$ \\ ${ }^{1}$ Cochrane Institute of Primary Care and Public Health, Cardiff University \\ ${ }^{2}$ School of Medicine, University of Buenos Aires \\ ${ }^{3}$ TIME Institute, Cardiff University
}

Correspondence concerning this article should be addressed to Julieta Galante, Cochrane Institute of Primary Care and Public Health, Cardiff University, 5th Floor, Neuadd Meirionnydd, Heath Park, Cardiff, CF14 4XN, United Kingdom. E-mail: galantej@cardiff.ac.uk 


\section{Abstract}

Objective: Kindness-based meditation $(\mathrm{KBM})$ is a rubric covering meditation techniques developed to elicit kindness in a conscious way. Some techniques, e.g., loving-kindness meditation and compassion meditation, have been included in programs aimed at improving health and wellbeing. Our aim was to systematically review and meta-analyze the evidence available from randomized controlled trials (RCTs) comparing the effects of KBM on health and wellbeing against passive and active control groups in patients and in the general population. Method: Searches were completed in March 2013. Two reviewers applied predetermined eligibility criteria (RCTs, peer-reviewed publications, theses or conference proceedings, adult participants, KBM interventions) and extracted the data. Meta-analyses used random effects models. Results: Twenty-two studies were included. KBM was moderately effective in decreasing self-reported depression (standard mean difference (Hedges's g) -0.61, 95\% confidence interval (CI) $[-1.08,-0.14])$ and increasing mindfulness (Hedges's $g$ 0.63, 95\% CI [0.22, 1.05]), compassion (Hedges's g 0.61, 95\% CI [0.24, 0.99]) and self-compassion (Hedges's g 0.45, 95\% CI [0.15, 0.75]) against passive controls. Positive emotions were increased (Hedges's $g$ 0.42, 95\% CI [0.10, 0.75]) against progressive relaxation. Exposure to KBM may initially be challenging for some people. Results were inconclusive for some outcomes, in particular against active controls. The methodological quality of the reports was low to moderate. Results suffered from imprecision due to wide confidence intervals deriving from small studies. Conclusions: KBM showed evidence of benefits for the health of individuals and communities through its effects on wellbeing and social interaction. Further research including well-conducted large RCTs is warranted. Keywords: meditation, kindness, systematic review, meta-analysis, wellbeing 
Effect of Kindness-Based Meditation on Health and Wellbeing: A Systematic Review and Meta-Analysis

Meditation, "a family of self-regulation practices that focus on training attention and awareness in order to bring mental processes under greater voluntary control" (Walsh \& Shapiro, 2006, p. 228), has shown encouraging results in relation to improving health and wellbeing (Brand, Holsboer-Trachsler, Naranjo, \& Schmidt, 2012; Davidson \& McEwen, 2012; Kaliman et al., 2014; Ospina et al., 2007; Sedlmeier et al., 2012). Many meditative practices have gained acceptance in Western cultures. One of the most popular meditative practices nowadays is mindfulness meditation, which cultivates a state of nonjudgmental awareness of the present moment. Mindfulness is now part of mainstream psychotherapeutic interventions and people worldwide resort to it as a means to manage stress (J. M. G. Williams \& Kabat-Zinn, 2011).

The development of kindness, compassion and altruistic behavior is a well-recognized goal in most spiritual traditions (Kristeller \& Johnson, 2005). Meditation techniques developed to elicit kindness can be found in many of these traditions although the names, details and context vary widely. Examples of these techniques are loving-kindness meditation (LKM), compassion meditation and Christian contemplation. Kindness-based meditation $(\mathrm{KBM})$ is used here as a rubric covering these practices. Loving-kindness meditation (LKM) is one of the most popular KBM techniques and consists of the inner cultivation of a loving acceptance feeling towards all sentient beings (Salzberg, 1995). Its name and most traditional format come from Buddhism and it is practiced along mindfulness. The focus of the exercises is to engage a particular aspect of self, but in a mindful rather than analytic or judgmental way (Kristeller \& Johnson, 2005). While other forms of meditation may cultivate in practitioners only a heightened awareness of the self, KBM techniques aim to more strongly induce a harmonization with the needs of others (Kristeller \& Johnson, 2005). Traditional 
LKM advocates the following structured approach: directing caring feelings towards oneself, then towards loved ones, then towards acquaintances, then strangers, then towards someone with whom one experiences interpersonal difficulties, and finally to all beings without distinction. Exercises most often involve the repetition of short phrases (e.g., I wish you peace and joy) or the visualization of light flowing from oneself to others, aiming at generating a feeling of loving kindness towards the object of the meditation. Compassion meditation is a special form of LKM in which kindness is directed towards those who are suffering. One intervention that uses compassion meditation is Cognitively-Based Compassion Training, designed to improve wellbeing and ethical sensibility (Ozawa-de Silva, Dodson-Lavelle, Raison, \& Negi, 2012). Some interventions were specifically developed to work on increasing compassion for the self. One of them is mindful self-compassion, an approach for clinical and non-clinical populations that uses predominantly but not only KBM exercises (Neff \& Germer, 2013).

There is a wealth of experimental evidence supporting the hypothesis that being altruistic and even thinking of giving enhances the giver's health and wellbeing (Aknin, Dunn, \& Norton, 2012; Dunn, Aknin, \& Norton, 2008). A case has been made for governments to take more advantage of the links between altruism and wellbeing and find ways of promoting altruism as a matter of public health (Dunn et al., 2008).Data seem to show a positive feedback loop: people who feel better and healthier volunteer or donate more, and in turn voluntary work has a positive effect on health and wellbeing (Thoits \& Hewitt, 2001). A study found that LKM training increased positive emotions which in turn, as predicted by the Build and Broaden theory, increased psychological and physical resources, leading to improvements in wellbeing (Fredrickson, Cohn, Coffey, Pek, \& Finkel, 2008). From a public health point of view an empathic population is not only desirable because givers are bound to experience more health and wellbeing, but also because of the impact of 
altruistic actions on receivers. Improving communities' wellbeing through facilitating kindness could have far-reaching benefits and is an achievable goal. Experimental studies demonstrated the potential teachability of giving money and time to others (Dunn et al., 2008; Switzer, Simmons, Dew, Regalski, \& Wang, 1995), and that playing prosocial games led to subsequent prosocial behavior (Rosenberg, Baughman, \& Bailenson, 2013). Therefore, because of its pro-social objectives, KBM could provide distinct benefits from the societal point of view in comparison with other meditation techniques (Kristeller \& Johnson, 2005).

The number of scientific studies assessing the effects of KBM on health and wellbeing is growing and reviews covering some aspects have been published. A narrative review about loving-kindness and compassion meditation was published in 2011 (Hofmann, Grossman, \& Hinton). After reviewing psychological, neuroendocrine and neurobiological effects authors concluded that loving-kindness and compassion meditation may be useful for targeting psychological problems that involve interpersonal processes although findings are very preliminary. Another narrative review concluded that there is preliminary evidence that LKM can increase self-compassion and other-focused concern (I. Boellinghaus, Jones, \& Hutton, 2012). Ozawa-de Silva et al. examined the potential individual and social benefits of compassion training and presented ongoing research programs for its study (2012). A systematic review and meta-analysis of cross-sectional studies exploring the relationship between self-compassion and mental health found that higher levels of self-compassion were associated with lower levels of mental health symptoms, although the crosssectional design preclude inferring causality (Macbeth \& Gumley, 2012, p. 551).

A comprehensive and quantitative review of KBM research is clearly lacking. Our aim was to provide the first systematic review and meta-analysis of the evidence available from randomized controlled trials (RCTs) investigating the effects of KBM on health and wellbeing in patients and in the general population. 


\section{Methods}

The review protocol has been prospectively registered in PROSPERO (Julieta Galante, Galante, Bekkers, \& Gallacher, 2012).

\section{Literature search and study selection}

In March 2013 the following databases were searched: CENTRAL (Issue 2 of 12, February 2013), MEDLINE (1946 to March week 22013 plus in-process), EMBASE (1947 to March 2013), AMED, PsycINFO (1806 to March week 3 2013), CINAHL Plus, ASSIA and Google Scholar. For the search strategy the search terms love, kindness, compassion, forgiveness, empathy, maitri, metta, mudita, karuna, upekkha, chesed, sympathetic joy, equanimity and Christian were combined with the terms meditation, self-induction, training or cultivation and adapted to each search engine using sensitive filters for randomized controlled trials. Articles written in English, Spanish, Italian, Portuguese, French, Dutch and German were included. Two reviewers independently excluded reports that did not meet inclusion criteria based on title and abstract. Full published reports were obtained for the remainder, and inclusion criteria were applied. References were scanned for further RCTs.

\section{Inclusion criteria}

Included studies were: (a) RCTs; (b) published in peer-reviewed journals, theses or conference proceedings; (c) included adult participants only; (d) measured outcomes related to health and/or wellbeing; and (e) included an intervention which was mainly a form of KBM. Interventions were considered as mainly a form of KBM if: (a) the explicit main objective of the intervention was to purposively generate kindness in some if its forms; and (b) KBM exercises were predominant (i.e., more than $50 \%$ of the exercises or sessions included some form of KBM). Where this was not clear the full text was retrieved and if it was still not clear the study was excluded. In some traditions, such as Buddhist or Christian, kindness is at the very roots of their teachings, therefore studies that examine meditation 
practices in the context of these traditions are implicitly aimed at purposively generating and expanding kindness. For the purposes of this review explicit objectives were taken into consideration rather than those referenced by the context in which the practices took place.

Interventions aimed at eliciting predominantly self-kindness, provided they were meditation-based, were included as a sub-group, as self-kindness and kindness towards others have shown to be closely linked (Neff \& Pommier, 2012). Methods of exploring and eliciting kindness in a conscious way other than through meditation (e.g., Kelly, 2012; Lincoln, Hohenhaus, \& Hartmann, 2012; M. May, 2005; Standard, 2004), although worthy of study, are beyond the scope of this review. Studies without outcomes related to health and/or wellbeing (e.g., neuroimaging) were not included. Similarly, for the included studies, outcomes not related to health and/or wellbeing, or analyses other than comparing randomized groups with each other are not reported.

\section{Data extraction and assessment of methodological quality}

Study characteristics and risk of bias data were extracted independently by two reviewers and entered into data extraction forms piloted and designed for the review. A third review author was consulted regarding any discrepancies and these were resolved by discussion until consensus was reached. Studies were assessed for methodological quality according to the Cochrane Collaboration's tool for assessing risk of bias (J. P. T. Higgins et al., 2011). This tool is neither a scale nor a checklist. It is a domain-based evaluation, in which critical assessments are made separately for each of seven different domains: sequence generation, allocation concealment, blinding of participants and personnel, blinding of outcome assessment, incomplete outcome data, selective outcome reporting and 'other issues'. Within each domain, what was reported to have happened in the study is described in sufficient detail to support a judgment about the risk of bias. This judgment can be 'Low risk' of bias, 'High risk' of bias, or 'Unclear risk' of bias. 


\section{Analysis}

Primary outcomes defined for this review were wellbeing, quality of life, pain, depression, anxiety and stress. Secondary outcomes were altruism, empathy, compassion, mindfulness and adverse effects. Studies were grouped according to the comparison being made, type of outcome investigated and follow-up period. If appropriate data from at least two studies informing the same outcome were available a meta-analysis was conducted using Review Manager Software (version 5.2: Nordic Cochrane Centre, Copenhagen, Denmark). Data using the same measure which were reported as continuous variables (or scales with a sufficient number of points to treat variables as continuous) were pooled using the mean difference $(M D)$ with a 95\% confidence interval $(95 \% \mathrm{CI})$. When different measures were used to evaluate the same result in a comparison, data were grouped by calculating the standardized mean difference (Hedges's $g$ ) with 95\% CI (1985). Its magnitude can be interpreted using Cohen's convention as small (0.2), medium (0.5), and large (0.8) (1988). Dichotomous outcomes were analyzed by calculating relative risk (RR) grouped in each comparison. Final values were used where possible. To obtain more conservative estimates a random effects model was conducted. To determine whether combining results was appropriate tests of heterogeneity were performed using $\chi^{2}$ (Cochran's $Q$ ) and $\mathrm{I}^{2}$ statistics. $\chi^{2}$ calculates the probability for observed differences in results to be compatible with chance alone, and $\mathrm{I}^{2}$ assesses the degree of inconsistency across studies (J. P. Higgins, Thompson, Deeks, \& Altman, 2003). The P-value for $\chi^{2}$ was set conservatively at 0.1 . $\mathrm{I}^{2}$ band values were interpreted according to the Cochrane Reviewers' Handbook (J. P.T. Higgins \& Green, 2011), which considers the possibility of moderate heterogeneity with $\mathrm{I}^{2}$ values above $30 \%$ and the chance of substantial heterogeneity with values above $50 \%$. Pre-specified subgroup analyses were conducted according to the studied population (patients or general population), the length of the intervention (less than 1 week versus more than 1 week), and the type of 
intervention (interventions cultivating kindness in general versus those focused on selfkindness).

When authors presented their data as means and standard deviations it was assumed that the data were normally/near-normally distributed. Data were also assumed to be independent although this may not always be the case in interventions with a strong group component. Subscales were not reported if they formed part of a reported scale. Pre-specified sensitivity analyses were conducted in meta-analyses of at least three studies to explore the influence of studies with low methodological quality. In order to do this, the studies in the meta-analysis with the lowest number of low risk of bias judgments in the risk of bias assessment were removed and the result was considered stable if significance was maintained. Funnel plots were used to investigate publication bias if a meta-analysis of at least five studies could be performed with no significant heterogeneity.

\section{Results}

\section{Results of the search}

Thirty-three records meeting the selection criteria were identified (see Figure 1). Eight of these were found through reference search or authors' communication. Eight records were dissertations (Cohn, 2008; Humphrey, 1999; Kleinman, 2010; Law, 2011; Lipizzi, 2011; Mascaro, 2011; Templeton, 2007; Weibel, 2007 ) and three were conference papers (Desbordes, Negi, Raison, \& Schwartz, 2012; McGillicuddy, Dalton, Chakoian, Swanson, \& Feldman, 2010; Weng, Lewis-Peacock, Stodola, \& J.Davidson, 2012). Detail of records that were close to meeting the eligibility criteria can be found in Supplemental Table 1 in the online Supplemental Materials. No records were excluded for language restrictions. All the relevant full-text articles could be retrieved.

Twenty-two studies (1747 participants) were included as some studies reported their outcomes in multiple publications. Five studies were only reported in dissertations 
(Humphrey, 1999; Kleinman, 2010; Law, 2011; Templeton, 2007; Weibel, 2007 ). The studies reported in conference papers were also published in full-text format. Eight records

(Desbordes et al., 2012; Desbordes et al., 2012; Kleinman, 2010; Lipizzi, 2011; Mascaro, 2011; Mascaro, Rilling, Negi, \& Raison, 2013a, 2013b; Pace et al., 2009) belong to the same study (B. M. Kleinman, personal communication, April 17, 2013) but used different subpopulations. Because these publications differ in various aspects (sub-populations, arms, outcomes and analyses) they were treated as separate studies throughout this review. The only exception was for the meta-analyses, in which these publications were treated as one study in order to avoid participant overlap.

\section{Characteristics of included studies}

The characteristics of included studies are provided in Table 1 . More than $60 \%$ of the included studies have been published from 2010 onwards, reflecting a growing interest in this research area. Studies were small, with a median total number of participants of 65 (range 23 to 202). All but two studies (Crane, Jandric, Barnhofer, \& Williams, 2010; Wallmark, Safarzadeh, Daukantaite, \& Maddux, 2013) took place in the United States.

Intervention. Although all the included studies used KBM as the predominant component of their interventions, the formats, foci and names of the interventions varied. Eleven studies used LKM, eight studies focused their interventions on compassion, one study focused on self-compassion, one focused on Buddhist concepts and one on forgiveness. Fourteen studies used interventions which lasted more than one week, one intervention lasted three days and the others lasted less than half an hour. Most of the long interventions (i.e. more than a week) had weekly group sessions and encouraged participants to practice daily at home, usually through audio recorded instructions. Four of these long interventions were entirely or almost entirely distance-based using audio recorded sessions and two of them included feedback sessions. Most studies with long interventions reported rates of attendance 
to the sessions which were high (75\% or more) (Carson et al., 2005; Condon, Desbordes, Miller, \& DeSteno, 2013; Fredrickson et al., 2008; Jazaieri et al., 2012; Koopmann-Holm, Sze, Ochs, \& Tsai, 2013; C. J. May, Weyker, Spengel, Finkler, \& Hendrix, 2012; Pace et al., 2009; Weibel, 2007 ; Weng et al., 2013).

Comparisons. Twelve studies compared the intervention against passive control groups (waitlists, standard care, rest, non-interventions) whilst fourteen compared it against active interventions (massage, progressive relaxation, neutral imagery induction, face visualization, health discussion, breathing meditation, mindfulness meditation, concentration meditation, cognitive appraisal, improvisational theater). Seven studies had more than two arms (either a combination of passive and active control groups, or two active groups, or factorial designs combining interventions).

Participants. Ten studies recruited adults from the general population, nine studies recruited undergraduate students and three studies recruited patients. Most studies included more women than men and three included women only. Ten studies reported that their participants had little or no prior meditation experience (Carson et al., 2005; Condon et al., 2013; Crane et al., 2010; Desbordes et al., 2012; Feldman, Greeson, \& Senville, 2010; Fredrickson et al., 2008; Hutcherson, Seppala, \& Gross, 2008; Koopmann-Holm et al., 2013; Wallmark et al., 2013; Weng et al., 2013) and one reported that most participants had prior meditation experience (Neff \& Germer, 2013).

In most studies participants were rewarded for taking part with money (USD10 to USD65) (Carson et al., 2005; Condon et al., 2013; Fredrickson et al., 2008; Hutcherson et al., 2008; Kleinman, 2010; Templeton, 2007; Weibel, 2007 ; Weng et al., 2013), raffles (Condon et al., 2013), small prizes(Crane et al., 2010), reduced fees for the course (Neff \& Germer, 2013) or credits for undergraduates (Feldman et al., 2010; Hunsinger, Livingston, \& Isbell, 
2013; Kleinman, 2010; Law, 2011; Pace et al., 2009; Weibel, 2007 ). One study reported that no reward was offered (Jazaieri et al., 2012).

\section{Methodological quality}

Methodological quality is outlined in Supplemental Table 2 (online Supplemental Materials). This detailed table contains study descriptions that support each risk of bias judgment. Half of the risk of bias criteria could not be clearly defined due to lack of reporting detail. All authors were contacted with the aim to achieve a more informative risk of bias assessment as recommended by recent evidence (Vale, Tierney, \& Burdett, 2013), although not all of them replied. No studies had a low risk of bias in every category. On average, 29\% of the categories per study had a low risk of bias.

Thirteen studies $(60 \%)$ reported adequate randomization sequence generation procedures (Carson et al., 2005; Crane et al., 2010; Desbordes et al., 2012; Humphrey, 1999; Jazaieri et al., 2012; Kleinman, 2010; Koopmann-Holm et al., 2013; Mascaro et al., 2013a; Neff \& Germer, 2013; Pace et al., 2009; Wallmark et al., 2013; Weibel, 2007 ; A.-L. Williams, Selwyn, Liberti, et al., 2005). Nine studies (41\%) reported adequate allocation concealment procedures (Carson et al., 2005; Crane et al., 2010; Desbordes et al., 2012; Humphrey, 1999; Kleinman, 2010; Koopmann-Holm et al., 2013; Mascaro et al., 2013a; Pace et al., 2009; Weibel, 2007 ). Due to the nature of the intervention double blinding could not be implemented, but in some lab studies with one-day interventions and very similar control groups it is possible that participants who had no previous experience of meditation failed to realize their allocation to control or intervention group (Feldman et al., 2010; Hutcherson et al., 2008; Law, 2011; Templeton, 2007). Unfortunately, not enough details were provided in order to confirm this likelihood so the risk of bias is unclear. Eight studies reported that support staff (excluding intervention facilitators) were blind to allocation (Carson et al., 2005; Condon et al., 2013; Desbordes et al., 2012; Hunsinger et al., 2013; Kleinman, 2010; 
Mascaro et al., 2013a; Pace et al., 2009; A.-L. Williams, Selwyn, Liberti, et al., 2005). There were self-reported outcomes in almost all the included studies (i.e., participants acted as outcome assessors). However, assessors were blind to those outcomes that were not selfreported in four studies (Condon et al., 2013; Desbordes et al., 2012; Mascaro et al., 2013a; Pace et al., 2009).

Eleven studies, many of them with one-day interventions, had low risk of attrition bias (Crane et al., 2010; Feldman et al., 2010; Hunsinger et al., 2013; Hutcherson et al., 2008; Jazaieri et al., 2012; Kleinman, 2010; Law, 2011; Mascaro et al., 2013a; C. J. May et al., 2012; Templeton, 2007; Weng et al., 2012). The main problems in studies with long interventions were high attrition and the fact that no reasons were provided for dropping-out. Attrition was unbalanced in many cases but no study had more attrition in the kindness-based intervention group compared to other active control groups. Therefore, drop-outs may be related to the time and duration of commitment required rather than to the content of the intervention (e.g., adverse effects).

Seven studies performed an intention-to-treat analysis, almost all of them having oneday interventions (Crane et al., 2010; Feldman et al., 2010; Fredrickson et al., 2008; Hutcherson et al., 2008; Jazaieri et al., 2012; Templeton, 2007; A.-L. Williams, Selwyn, Liberti, et al., 2005). One study was at low risk of selective reporting because a publicly available protocol was published before the study took place (Desbordes et al., 2012). One study reported a primary outcome on which sample size calculations were done (A.-L. Williams, Selwyn, Liberti, et al., 2005).

\section{Effects of the intervention}

The results for each comparison are presented below. KBM was tested in RCTs against eight comparison groups, seven of them active. Follow-up measures were generally not made. One study had a follow-up period of 64 weeks (A.-L. Williams, Selwyn, Liberti, et 
al., 2005), one of three months (Carson et al., 2005) and one of two months (Weibel, 2007 ). In relation to this review's pre-specified primary outcomes, there were no studies which used a direct wellbeing scale, although associated concepts were analyzed. Meta-analyses could be conducted for two comparisons and nine outcomes. Some meta-analyses gave heterogeneous results so the sub-group analyses or individual studies were reported. Sensitivity analyses were conducted for two outcomes. Funnel plots could not be performed. Results of metaanalyses are presented in the text, while meta-analysis forest plots and results of individual studies are presented in supplemental tables and figures (online Supplemental Materials) and discussed in the text.

Comparison 1: KBM versus passive control groups. A summary of the results can be found in Supplemental Table 3. Twelve studies contributed to this comparison (Carson et al., 2005; Condon et al., 2013; Crane et al., 2010; Fredrickson et al., 2008; Humphrey, 1999; Hunsinger et al., 2013; Jazaieri et al., 2012; Neff \& Germer, 2013; Wallmark et al., 2013; Weibel, 2007 ; A.-L. Williams, Selwyn, Liberti, et al., 2005).

Improving wellbeing. No significant differences were found in satisfaction with life $\left(M D 0.19,95 \%\right.$ CI $[-0.83,1.21]$, significant heterogeneity: $\chi^{2}=4.05, d f=1(\mathrm{p}=0.04), \mathrm{I}^{2}=$ 75\%; see Supplemental Figure 1) quality of life (A.-L. Williams, Selwyn, Liberti, et al., 2005) and happiness (Neff \& Germer, 2013). Positive emotions were significantly higher in one study's adherent analysis (Fredrickson et al., 2008), but this was not confirmed in the intention-to-treat analysis and in another study (Koopmann-Holm et al., 2013). However, when ideal affect (how people ideally want to feel) was measured, intervention participants valued low-arousal positive states such as calm more than control participants (KoopmannHolm et al., 2013).

Reducing suffering. A meta-analysis of three studies found that intervention participants reported significantly less stress (Hedges's $g-0.46,95 \%$ CI [-0.82, - -0.10]; 
heterogeneity tests: $\chi^{2}=2.21, d f=2(p=0.33), I^{2}=9 \%$; see Supplemental Figure 2$)$, but this significance was lost in the sensitivity analysis (Hedges's $g-0.29,95 \%$ CI [-0.70, 0.12]; heterogeneity tests: $\chi^{2}=0.09, d f=1(\mathrm{p}=0.77), \mathrm{I}^{2}=0 \%$; see Supplemental Figure 10$)$. The effect was greater in the sub-group of participants from the general public and KBM directed mainly towards others, although there was only one study in this sub-group (Wallmark et al., 2013). Studies evaluating the reduction of anxiety against control participants yielded mixed results and there was statistical heterogeneity in the meta-analysis ( $M D-5.60,95 \%$ CI [$12.96,1.76]$; heterogeneity tests: $\chi^{2}=14.67, d f=0(\mathrm{p}=0.0007), \mathrm{I}^{2}=86 \%$; see Supplemental Figure 3), although an intervention focused on self-compassion significantly reduced anxiety (Neff \& Germer, 2013). No significant differences were detected for negative emotions (Fredrickson et al., 2008; Koopmann-Holm et al., 2013).

A meta-analysis for the outcome depression revealed that intervention participants were significantly less depressed than their peers in the control group (Hedges's $g-0.61,95 \%$ CI [-1.08, -0.14]; heterogeneity tests: $\chi^{2}=0.03, d f=1(\mathrm{p}=0.85), \mathrm{I}^{2}=0 \%$; see Supplemental Figure 4). There is no evidence of pain being reduced in patients with chronic low back pain in comparison to treatment as usual (Carson et al., 2005).

Kindness and social domains. Participants randomized to the intervention were more compassionate (Hedges's $g$ 0.61, 95\% CI [0.24, 0.99]; heterogeneity tests: $\chi^{2}=0.07, d f$ $=1(\mathrm{p}=0.78), \mathrm{I}^{2}=0 \%$; see Supplemental Figure 5) and more self-compassionate (Hedges's $g$ $0.45,95 \%$ CI $[0.15,0.75]$; heterogeneity tests: $\chi^{2}=0.22, d f=2(\mathrm{p}=0.89), \mathrm{I}^{2}=0 \%$; stable in sensitivity analysis, see Supplemental Figures 6 and 11). Effects on self-compassion were greater in the study delivering an intervention focused on self compassion (Neff \& Germer, 2013), and may be longer-lasting than other effects as one study shows evidence of impact at 2-months follow-up (Weibel, 2007 ). Compassion in one trial was not significant but this was measured using a single item (Fredrickson et al., 2008). Regarding anger, results suggest 
KBM reduces the expression of anger towards other persons or objects by improving control (Carson et al., 2005).

Fears of Compassion Scales measure worries about showing that one is compassionate to self and others, with items like "I fear that being too compassionate makes people an easy target”. KBM appears to reduce these fears (Jazaieri et al., 2012). No significant differences were found for empathy (Wallmark et al., 2013), forgiveness (Humphrey, 1999), or social connectedness (Neff \& Germer, 2013). Helping behavior was greater in the intervention group although the difference was not significant (Condon et al., 2013).Affective learning refers to the process of associating positivity or negativity with neutral stimuli. Findings showed that participants in the intervention group associated neutral stimuli with positivity, but not with negativity, to a greater degree than control participants, even after a short training in KBM (Hunsinger et al., 2013).

Mindfulness and related concepts. Intervention trainees were significantly more mindful (Hedges's $g$ 0.63, 95\% CI [0.22, 1.05]; heterogeneity tests: $\chi^{2}=0.06, d f=1(\mathrm{p}=$ $0.81), I^{2}=0 \%$; see Supplemental Figure 7). Self-compassion training reduced the avoidance of difficult thoughts and feelings after a stressful event (Neff \& Germer, 2013).

Conditional goal setting refers to "the tendency of some people to regard happiness and other similar high-order goals, as pursuable and achievable through attainment of particular lower-order outcomes (e.g., I can only be happy if I am financially secure, doing well at work or in a romantic relationship)" (Crane et al., 2010, p. 205). Contrary to expectation, 15 min of KBM increased conditional goal setting compared to passive controls.

Cognition. After three training sessions, intervention participants performed significantly better than control participants in the Stroop test, a measure of cognitive control which involves several attentional processes (Hunsinger et al., 2013). 
Comparison 2: KBM versus progressive relaxation. A summary of the results is presented in Supplemental Table 4. Two studies contributed to this comparison (Feldman et al., 2010; Templeton, 2007).

Improving wellbeing. Intervention participants experienced significantly more positive emotions (Hedges's $g$ 0.42, 95\% CI [0.10, 0.75]; heterogeneity tests: $\chi^{2}=1.36, d f=1$ $(p=0.24), I^{2}=27 \% ;$ see Supplemental Figure 8).

Reducing suffering. No significant differences were detected for negative emotions (Feldman et al., 2010).

Kindness and social domains. Compassion was meta-analyzed but there was evidence of statistical heterogeneity (Hedges's $g$, 95\% CI 0.54 [-0.29, 1.37]; heterogeneity tests: $\chi^{2}=8.28, d f=1(\mathrm{p}=0.004), \mathrm{I}^{2}=88 \%$; see Supplemental Figure 9). The individual studies gave mixed results. There is no evidence of intervention participants judging moral transgressions less harshly than those assigned to progressive relaxation, indicating that increased compassion may not necessarily result in increased tolerance of behaviors that harm others (Templeton, 2007). Groups did not significantly differ on spiritual transcendence (Templeton, 2007).

Mindfulness and related concepts. A further outcome is decentering, which involves "view(ing) thoughts as events in the mind rather than necessarily being reflections of reality or accurate self-view" (Feldman et al., 2010, p. 1002). Decentering was not significantly higher in the KBM group in comparison with the progressive relaxation group. Frequency and negative reactions to repetitive thoughts were not significantly different between groups.

\section{Comparison 3: KBM versus mindfulness/ concentrative meditation. A} summary of the results can be found in Supplemental Table 5. Seven studies contributed to 
this comparison (Condon et al., 2013; Crane et al., 2010; Desbordes et al., 2012; Feldman et al., 2010; Kleinman, 2010; Koopmann-Holm et al., 2013; C. J. May et al., 2012).

Improving wellbeing. Results were mixed regarding positive emotions, with two studies indicating no differences (Koopmann-Holm et al., 2013; C. J. May et al., 2012), and one study showing that KBM practitioners felt more positive than those practicing mindfulness (Feldman et al., 2010). There were no differences in ideal affect or satisfaction with life (Koopmann-Holm et al., 2013).

Reducing suffering. Anxiety, depression (Desbordes et al., 2012), and negative emotions (Feldman et al., 2010; C. J. May et al., 2012) were not significantly different between groups.

Kindness and social domains. No significant differences were detected for the outcomes helping behavior (Condon et al., 2013) and compassion (Feldman et al., 2010; Kleinman, 2010), nor is there evidence of less attachment-related avoidance (discomfort depending on others) and attachment-related anxiety (anxiety regarding trust in others' availability) with KBM compared to mindfulness (Kleinman, 2010).

Mindfulness and related concepts. Mindfulness was not significantly different in these groups (C. J. May et al., 2012). Decentering was higher in those randomized to mindfulness meditation, which is not surprising given that this is one of the objectives in mindfulness meditation (Feldman et al., 2010). Frequency and negative reactions to repetitive thoughts were not significantly different between groups (Feldman et al., 2010). Similar to studies with passive controls, 15 min of KBM increased conditional goal setting compared to controls practicing mindfulness (Crane et al., 2010).

Comparison 4: KBM versus health discussion group. A summary of the results can be seen in Supplemental Table 6. Four studies contributed to this comparison (Desbordes et al., 2012; Kleinman, 2010; Lipizzi, 2011; Mascaro, 2011). 
Reducing suffering. Intervention participants were more stressed than participants attending a health discussion group (Mascaro, 2011). No significant differences were found in depression and degree of aversion to experiencing pain or aversion to watching pain in others (Desbordes et al., 2012; Mascaro et al., 2013b). There were no differences in coping styles (Kleinman, 2010), and self-reported issues related to body image (Lipizzi, 2011).

Kindness and social domains. No significant differences were detected for the outcomes helping behavior (Mascaro, 2011), compassion, connectedness and attachmentrelated anxiety or avoidance (Kleinman, 2010). Participants practicing KBM had more empathic accuracy (the ability to infer others' mental states from facial expressions) than those in the health discussion group, but there is no evidence they had more empathic concern (Kleinman, 2010; Mascaro et al., 2013a). In addition, here were no differences in post socialstress task plasma concentrations of interleukin (IL)-6 (an indicator of immune response) and cortisol (Pace et al., 2009).

Comparison 5: KBM versus neutral visualization. A summary of the results is available in Supplemental Table 7. Two studies, both with one-day interventions, contributed to this comparison (Hutcherson et al., 2008; Law, 2011).

Improving wellbeing. Post-intervention positive mood scores were significantly improved (Hutcherson et al., 2008). Post-intervention physiological measures were not significantly different between groups (Law, 2011). However, KBM practitioners had a lower respiratory rate and an increased respiratory sinus arrhythmia during the intervention, indicating greater relaxation.

Reducing suffering. Negative mood was not significantly different between groups (Hutcherson et al., 2008).

Kindness and social domains. Helping behavior did not show any significant differences between groups (Law, 2011). Explicit (self-reported) and implicit (affective 
priming) evaluations of photographs of the self and others were significantly different between groups: intervention participants felt more connected, similar and positive towards the subject shown (Hutcherson et al., 2008). However, a very similar protocol used in another study showed no significant differences (Law, 2011). None of the outcomes assessing social stress tasks were significantly different between groups (Law, 2011).

Cognition. Cognitive control was not significantly different between groups (Law, 2011).

Comparison 6: KBM versus cognitive reappraisal. Cognitive reappraisal is a psychological technique that aims to teach the client to reinterpret personally stressful events in order to decrease negative affect. A summary of the results can be seen in Supplemental Table 8. One study contributed to this comparison with one outcome (Weng et al., 2013). Helping behavior was significantly different between groups: intervention participants gave more money to a victim of an unfair situation in a redistribution game.

Comparison 7: KBM versus massage. A summary of the results is available in Supplemental Table 9. One study contributed to this comparison with one outcome (A.-L. Williams, Selwyn, Liberti, et al., 2005). Quality of life for end-of-life HIV positive patients was not significantly different between these groups either at one month or 64 weeks' followup.

Comparison 8: KBM versus improvisational theater. A summary of the results is available in Supplemental Table 10. One study contributed to this comparison with one outcome (Koopmann-Holm et al., 2013). Satisfaction with life was not significantly different between these groups. 


\section{Discussion}

\section{Main results}

Generally speaking, KBM has shown encouraging but inconsistent evidence of benefit for the health of individuals through its positive effects on outcomes related to wellbeing, and for the health of communities through its positive effects on outcomes related to social interaction.

Primary review outcomes and related concepts. Results indicate that KBM facilitates positive emotions, although they are not entirely consistent. There were no significant improvements in more stable measures of wellbeing such as quality of life or satisfaction with life. As it has been noted before (Fredrickson et al., 2008), there is no evidence that KBM practice affects negative emotions.

$\mathrm{KBM}$, as mindfulness meditation, promoted low-arousal positive states valuing. A main objective in most meditation practices is to attain a calm state that facilitates attentional processes and awareness. When learning to meditate, people may start to value low-arousal positive states such as calmness or peacefulness more. This may happen independently from the actual states so that the newly idealized states may be achieved later on or may never be achieved. It has been theorized that ideal affect is influenced by culture and may serve as a guide that directs individuals' behavioral choices, providing structure and meaning (Tsai, 2007). An increased valuing of low-arousal positive states in some members of the population could eventually lead to a cultural shift.

KBM reduces depression compared to passive controls, but the non-significant results against active controls (health discussion) are puzzling. The evidence regarding the reduction of anger, anxiety and stress is inconsistent. Physiological measurements revealed an increased state of relaxation during the intervention, although there is no evidence of such state being extended beyond the meditation period. 
Secondary review outcomes. The favorable effect of KBM on self-reported compassion (including self-compassion) compared to a passive control group was a robust outcome. Compared to active control groups the results were mixed. These self-reported results should be interpreted with caution as they could derive from expectancy effects/social desirability bias given that kindness and compassion are explicitly addressed during KBM training. Helping behavior, in turn, is an objective measure. Only one out of four measurements of helping behavior was significant, and it was against active controls.

Another outcome not likely to be affected by biases derived from self-report is affective learning: participants in the intervention group associated a larger proportion of neutral stimuli with positivity than passive controls. Shifts in affective learning are likely to have downstream effects on psychological processes such as attitude formation. For instance, individuals inclined to learn to associate positivity with neutral stimuli tend to show relatively lower levels of explicit and implicit racial prejudice (Livingston \& Drwecki, 2007).

There was no evidence of an increase in empathic concern. This may be because the scale that was used, which measures a trait, may not be sensitive to change. Outward direction of anger and fears of compassion were significantly reduced and perspective taking and mindfulness increased, although there was no direct evidence of the intervention enhancing social connections.

KBM improved cognitive control compared to a passive control group but results were not replicated against neutral visualization, a type of mental training. Unspecific effects derived from mental exercise may have influenced these results. The fact that participants had more empathic accuracy than controls also indicates that KBM may improve cognitive processes, in this case linked to emotional processes. This result was obtained against a health discussion intervention which, like passive controls, lacks focused mental exercises. 
Adverse effects were not explicitly measured by any of the studies. However, KBM increased conditional goal setting. Further analyses indicated that this effect was restricted to participants low in goal re-engagement (the ability to re-engage with new goals when existing goals become unattainable). It is recognized that people differ in their initial reactions to KBM and that it may take time for benefits to be noticed (Salzberg, 1995). For some people "initial exposure to loving-kindness meditation may only serve to increase the desire to be happy and hence the salience and importance of existing goals, without generating sufficient unconditional positive affect to enable alternative paths to fulfillment to become apparent" (Crane et al., 2010, p. 212). KBM is challenging in that it involves revising deep-seated emotions and it may initially generate an internal conflict with impulses and past experiences. Law found that receiving a brief session of LKM while being in a negative mood led to greater implicit negativity towards self and others, lower self-esteem during a social exclusion stressor and less reduction in heart rate after it (Law, 2011). This may have been due to LKM bringing attention to whatever feelings the participant was having in the moment, therefore negative feelings may have become accentuated in short training as there would have not been enough time to work with them (Law, 2011). Counterintuitive effects resulting from initial exposure to KBM may be a reason for attrition early in the training.

Effects in sub-groups. The variety of comparisons and outcomes made sub-group analyses difficult. Moreover, only two RCTs used clinical populations and only one tested a KBM intervention focused on self-compassion. Most studies tested long interventions (i.e., more than one week). However, six studies tested short interventions so differences between these sub-groups could be assessed non-quantitatively. A trend towards more significant results in long interventions compared to short interventions was not detected. Longer or more intensive interventions may be required. 
Some benefits appear to be restricted to those participants who practice the most. Several studies found a dose-response gradient in the KBM arm (Pace et al., 2009) (Carson et al., 2005; Fredrickson et al., 2008; Jazaieri et al., 2012; Wallmark et al., 2013). The need to practice in order to obtain benefit may be a reason why significant improvements in positive emotions were seen in adherent analyses but not in intention-to-treat analyses (Fredrickson et al., 2008). However, Leppma et al. found no evidence of consistent correlation between quantity of KBM and empathy, perceived social support, and problem-solving appraisal (Leppma, 2011). These inconsistencies could be related to individual differences in responsiveness to meditation practice (C. J. May et al., 2012).

Comparisons. Even though most studies compared KBM against passive controls, a variety of active control groups was used. Active comparators control for non-specific effects such as receiving caring attention, taking time out from one's regular schedule or taking positive action. KBM performed better against passive control groups than against active controls, suggesting that at least some of its effects were non-specific.

The generally non-significant results in the comparison against mindfulness/ concentrative meditation may be considered unsurprising given that the comparison groups were other meditative techniques. Compassion and helping behavior are the areas where a significant difference in favor of KBM would have been expected but results do not confirm this, indicating that other types of meditation may have an indirect effect on these areas.

Compared to progressive relaxation (a non-meditative exercise but certainly relaxing) KBM generates more positive emotions and may generate more compassion, confirming prior findings that this meditation is not just a relaxation technique (Sedlmeier et al., 2012). Results favor the intervention when compared to cognitive reappraisal, a much less emotional and more self-focused way of reflecting on relationships with others. The lack of significant differences in these areas when KBM was compared to health discussion is puzzling. 
Neutral visualization was a closely matched non-meditative mental control task, therefore participants without prior meditation experience may have been blind to assignment. Positive emotions were significantly stimulated by the intervention. In spite of KBM specifically addressing social domains, social stress was not significantly diminished in comparison with this control group.

\section{Comparing results with KBM studies other than RCTs}

Neuroimaging evidence suggests that KBM shares some effects with other types of meditation (Barnhofer, Chittka, Nightingale, Visser, \& Crane, 2010; Brewer et al., 2011), but may have less effect on tasks which demand focused attention (Lee et al., 2012), and more effect on tasks that require emotional processing (Desbordes et al., 2012). Indeed, qualitative research indicates that LKM is generally perceived as an intense but worthwhile experience. Beginners and advanced practitioners experience insights and shifts in their ethical views, but using LKM as a tool in difficult situations appears to be possible for experienced practitioners only, since beginners appear to have more problems to elicit LKM during stressful situations (I. A. Boellinghaus, 2011; Corcoran, 2007; Pryor, 2011).

Identifying predictors of engagement with the training might help identify individuals most likely to benefit. There are a number of trials that showed no significant differences between groups but found through a qualitative component that at least some of the intervention participants were benefited (Pace et al., 2013; Reddy et al., 2013; Walker, 2006; Wong, 2011). This may be related to inter-individual differences. Several qualitative studies detected that beginners reported varied experiences (I. A. Boellinghaus, 2011; Corcoran, 2007; Pryor, 2011; Walker, 2006). This could have created subgroups that could have diluted the main effect in trials. Individual differences may determine engagement with the training and thus lead to more hours of practice. This last factor has been found to predict effects of KBM (Cohn \& Fredrickson, 2010; Leiberg, Klimecki, \& Singer, 2011). A baseline degree of 
empathy and a low tendency to engage in brooding were related to a better initial engagement with KBM (Barnhofer et al., 2010; Mascaro et al., 2013b). A rapid positive impact of the training is associated with longer term practice (Cohn \& Fredrickson, 2010). Self-compassion interventions may be more suitable in people who have less chance of finding other-directed KBM beneficial. This needs to be explored.

The quality of the neuroimaging evidence in beginners is high because most of the evidence comes from RCTs (Barnhofer et al., 2010; Desbordes et al., 2012; Mascaro et al., 2013b; Weng et al., 2013). A review of the social influences on neuroplasticity concluded that the functional and structural changes observed with some forms of meditation, KBM included, suggest that wellbeing and prosocial characteristics might be enhanced through training (Davidson \& McEwen, 2012). They may generate a state of neurobehavioral functioning that is better than normal rather than a simple modulation of the adverse effects of stress. Studies on expert KBM practitioners are encouraging (e.g., Brewer et al., 2011; Lee et al., 2012; Lutz, Greischar, Perlman, \& Davidson, 2009). However, the long-term effects of KBM have so far only been studied cross-sectionally so reverse causality cannot be ruled out. A cohort study with a big sample size to control for several confounders would help to determine what the long-term effects of KBM are.

\section{Limitations of the reviewed studies}

The main limitations in the studies reviewed were small sample sizes, high attrition rates, low methodological quality and poor reporting. In addition, a lack of RCTs evaluating clinical applications of kindness based meditation was detected.

Small sample sizes are underpowered to detect small to moderate effect sizes (Jacob Cohen, 1992). Lack of power in individual studies is suggested for outcomes where individual studies were null but using a combined estimate did suggest an effect (see 
Supplemental Figures 2, 4, 6 and 8). The general lack of statistical power suggests that negative results should be considered as uninformative rather than definitively null.

High attrition was widely reported and is a major methodological issue in this area. However, high attrition is not specific to KBM but to course based interventions generally in which participant demand is high. Strategies for more informed recruitment and incentivizing for completion of psychological interventions are urgently required.

Many studies were poorly designed. Adequate randomization and concealment of allocation procedures were not reported in $40 \%$ and $60 \%$ of the studies respectively. Effect estimates from trials with inadequate or unclear randomization and concealment of allocation have been shown to be biased (Kjaergard, Villumsen, \& Gluud, 2001; Schulz, 1995). Sample size calculations were absent in almost all of the studies. Underpowered sample sizes lead almost inevitably to an imbalance in baseline values between groups (see Supplemental Table 2). A more extreme view is that unrealistic underestimates of trial size are unethical, as the results are unreliable and misleading (Pocock, 1983). It is apparent that studies involving psychological interventions are generally under-resourced.

Reporting standards need to be improved. Complete, clear and transparent information of the methodology and findings in published reports are necessary for readers to assess trials accurately (Kenneth, Douglas, \& David, 2010). Prospective trial registration in publicly available databases (e.g. ClinicaTtrials.gov) allows readers to understand the context of study results and discard design and publication biases (Irwin, 2007).

Only two RCTs evaluated clinical applications of KBM (Carson et al., 2005; A.-L. Williams, Selwyn, Liberti, et al., 2005). Uncontrolled studies have evaluated KBM in migraineurs successfully reducing pain (Tonelli, 2012), and in outpatients with schizophrenia-spectrum disorders increasing satisfaction with life and decreasing anhedonia and asociality (Johnson et al., 2011). However, uncontrolled studies may be severely biased 
so their results need to be confirmed in RCTs. Given its effects on positive emotions, mindfulness, depression, compassion and self-compassion, the therapeutic potential of these techniques is relevant to a wide range of mental and physical conditions. This needs to be explored, although care should be placed because initial exposure to KBM could be problematic in people with illness if their mood is very negative.

\section{Constraints of this review}

By limiting the review to RCTs, the best available evidence on the impact of KBM was considered. However, many non-randomized studies and neuroimaging studies containing valuable data were omitted. Because of the nature of the included studies, this review focused on the effect of meditation practices on beginners. KBM may generate different effects with long-term practice (Salzberg, 1995), therefore results should not be generalized to advanced or even intermediate practitioners. Effect sizes have to be interpreted with caution. A statistically significant difference or a Hedges's $g$ indicating a large standardized effect size do not necessarily mean they are clinically significant.

\section{Comparing results with other reviews}

Although this is the first systematic review of KBM, other reviews have covered similar ground. Hofmann et al. agreed with the present review that existing studies are in many ways preliminary, rather than definitive hypothesis tests (2011). Two more recent narrative reviews also highlight the need for robust large-scale designs (I. Boellinghaus et al., 2012), even blinded and with active control groups (Kok, Waugh, \& Fredrickson, 2013). It was also suggested that future research could identify the characteristics of and solutions for people who find LKM challenging (I. Boellinghaus et al., 2012). In their systematic review, Macbeth et al. concluded that "longitudinal datasets on changes in compassion over time, or indeed over treatment, are urgently required" (2012, p. 551). 


\section{Conclusions and the way forward}

To date, mindfulness has received much of the interest in the meditation research community. Over the last decade the quality of mindfulness research has progressively improved and training programs have become more standardized, leading to more robust and consistent findings (Julieta Galante, Iribarren, \& Pearce, 2012). A consequence of this process is the inclusion of mindfulness-based techniques into mainstream healthcare settings (Kendrick \& Peveler, 2010). Studies showing positive effects of mindfulness meditation on health and wellbeing paved the way for KBM to be examined.

This review shows that KBM has a promising potential for improving the health of individuals and the lives of entire communities. KBM was moderately effective in decreasing self-reported depression (Hedges's $g-0.61,95 \%$ CI [-1.08, -0.14]) and increasing mindfulness (Hedges's $g$ 0.63, 95\% CI [0.22, 1.05]), compassion (Hedges's $g$ 0.61, 95\% CI $[0.24,0.99]$ ) and self-compassion (Hedges's $g$ 0.45, 95\% CI $[0.15,0.75])$ against passive controls. Positive emotions were increased (Hedges's $g$ 0.42, 95\% CI [0.10, 0.75]) against progressive relaxation. However, results were mixed and complex. This should not be surprising. KBM training is a rich behavioral intervention that may have effects at many levels and with wide variation, making it difficult to evaluate. In addition, although the core exercises are standard, there is a variety of KBM techniques, as well as different teaching styles, and teachers with different abilities. All this adds extra layers of complexity. Various issues still need to be addressed before a robust evidence base can be established.

The RCTs reviewed here show that current KBM research is in its infancy. Trials tend to be small and with significant methodological limitations. The objectives tend to be mixed and exploratory - without setting primary outcomes/sample size calculations and without stringent measures to control for well-known biases - rather than focused and confirmatory. Well designed and well powered RCTs with a qualitative component are needed to investigate 
effects on beginners including inter-individual differences, and long term cohort studies are needed to study effects on experienced practitioners. Standardized KBM interventions should be manualized to guarantee uniform teacher training and to allow for replication studies, increasing the chance of detecting consistent findings. Judging by the growth in KBM research and increasing rigor in mindfulness meditation studies, it may be anticipated that the quality of KBM research will also improve with better designed and larger studies. 
Tables

Table 1

Characteristics of included studies.

\begin{tabular}{|c|c|c|c|c|c|c|}
\hline Study & NR & Participant characteristics & $\begin{array}{l}\text { Mean age } \\
\text { (years) }\end{array}$ & Women & Intervention & Control(s) \\
\hline 1 (Humphrey, 1999) & 23 & $\begin{array}{l}\text { Patients of gynecological medical } \\
\text { practice who have experienced } \\
\text { hurt in the past }\end{array}$ & $\begin{array}{l}45 \text { (range } \\
23-63)\end{array}$ & $100 \%$ & $\begin{array}{l}\text { Stress Management with forgiveness as } \\
\text { the goal (20-min taped practice for } 8 \\
\text { wks) }\end{array}$ & Waitlist \\
\hline $\begin{array}{l}2 \text { (Carson et al., 2005) })^{\star *} \text {, (Carson, } \\
2006)\end{array}$ & 61 & Chronic low back pain patients & $\begin{array}{l}51.1 \\
\text { (range 26- } \\
80)\end{array}$ & $61 \%$ & $\begin{array}{l}\text { LKM (8 x 90min group wkly sessions + } \\
10-30 \text { min daily taped practice) }\end{array}$ & Standard care \\
\hline $\begin{array}{l}3 \text { (A.-L. Williams, Selwyn, Liberti, } \\
\text { et al., 2005) }{ }^{* *},(\text { A.-L. Williams, } \\
\text { Selwyn, McCorkle, et al., 2005) }\end{array}$ & 58 & $\begin{array}{l}\text { Patients with AIDS near the end } \\
\text { of life non-demented \& living in a } \\
\text { nursing residence }\end{array}$ & $\begin{array}{l}45.09(\mathrm{SD} \\
8.5)\end{array}$ & $43 \%$ & $\begin{array}{l}\text { LKM (15-min daily taped practice for } 4 \\
\text { wks) }\end{array}$ & $\begin{array}{l}\text { (A) Massage (30-min } 5 \text { days a } \\
\text { wk for } 4 \text { wks). (B) Standard } \\
\text { care }\end{array}$ \\
\hline 4 (Templeton, 2007) & 85 & Undergraduate students & No data & $54 \%$ & LKM (1 taped session) & Progressive relaxation SS \\
\hline 5 (Weibel, 2007 ) & 71 & Undergraduate students & $\begin{array}{l}19.1(\mathrm{SD} \\
1.17)\end{array}$ & $77 \%$ & $\begin{array}{l}\text { LKM }(4 \text { x 90-min wkly sessions }+ \text { home } \\
\text { practice) }\end{array}$ & No intervention \\
\hline $\begin{array}{l}6 \text { (Fredrickson et al., 2008) } \\
(\text { Cohn, 2008), (Cohn \& }\end{array}$ & 202 & Company white collar employees & $\begin{array}{l}41(\mathrm{SD} \\
9.6)\end{array}$ & $60 \%$ & $\begin{array}{l}\text { LKM }(6 \times 60 \text {-min wkly sessions }+5 \text { days } \\
\text { a wk } 20 \text { min taped practice })\end{array}$ & Waitlist \\
\hline Fredrickson, 2010) & & & & & & \\
\hline
\end{tabular}


7 (Hutcherson et al., 2008)

8 (Pace et al., 2009) ${ }^{\star *}$, (Lipizzi, 2011)

9 (Crane et al., 2010) ${ }^{\star *}$, (Crane Jandric, Barnhofer, \& Williams, 2011)

10 (Feldman et al., 2010)**, (McGillicuddy et al., 2010)

11 (Kleinman, 2010)

12 (Desbordes et al., 2012) ${ }^{\star *}$, (Desbordes et al., 2012)

13 (Hunsinger et al., 2013)

14 (Jazaieri et al., 2012)
93 Appears to be general population
23.6
(range
18-40)

89 Medically healthy undergraduate students

18.5 (SD. $\quad 56 \%$

$0.7)$

55 Adult general population with no serious mental condition

27 (SD

9.62)

190 Undergraduate students (women's college)

19.83 (SD $\quad 100 \%$

59 Undergraduate students

18.42 (SD $\quad 40 \%$

$0.57)$

51 Medically healthy adult general

34.1 (SD

7.7)

population

20.5

$65 \%$

100 Adult general population with no serious mental condition
$57 \% \quad$ LKM (7-min single taped session)

Neutral imagery induction SS

Compassion meditation (50-min twice a Health discussion group SS wk for 6 wks + daily taped practice)

LKM (15-min single session)

(A) Breathing meditation SS.

(B) Rest SS

(A) Mindful breathing SS. (B) Progressive muscle relaxation SS.

Compassion meditation $(6 \times 2$-hr wkly sessions $+30-$ min daily taped practice)

(A) Mindful attention training

(B) Health discussion group SS

Cognitively-Based Compassion Training (A) Mindful attention training.

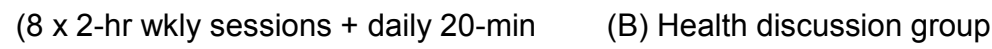
taped practice) SS

LKM (3 x 20-min sessions in a wk) No intervention

Compassion training $(8 \times 2-h r$ wkly Waitlist sessions + 15-30 min daily home taped practice) 
113 Undergraduate students

29 Medically healthy adult general population

$31 \quad$ Undergraduate students

17 (C. J. May et al., 2012)

18 (Wallmark et al., 2013)

19 (Weng et al., 2013) $)^{\star *}$, (Weng et

al., 2012)

20 (Condon et al., 2013)

21 (Neff \& Germer, 2013)

22 (Koopmann-Holm et al., 2013)
60 Adult general population with no serious mental condition

63 Adult general population with no serious mental condition

67 Adult non demented general population

54 Adult general population

96
Female students with no psychiatric symptoms
18.97 (SD $\quad 57 \% \quad$ LKM (10-min single taped session)

1.6)

31 (SD

$6.02)$

no data

$71 \%$

$33.8(\mathrm{SD}$
$12.93)$

$86 \%$

22.21 (SD $61 \%$

4.92)

25.23 (SD $74 \%$

4.66)

50.16 (SD $\quad 80 \%$

11.81)

21.13 (SD $\quad 100 \%$

$3.49)$

$45 \%$

Cognitively-Based Compassion Training

(8 $\times$ 2-hr wkly sessions + daily home taped practice)

LKM (20-min guided meditation once as an instruction +15 min at home per day on 3 days per wk during 5 wks).

\section{Four immeasurables \& Tonglen}

meditation $(8 \times 75-$ min sessions + daily taped practice)

\section{Compassion meditation (30-min daily} taped sessions for 2 wks)

Compassion meditation $(8 \times 2$-hr wkly sessions $+20-\min$ taped practice)

Mindful Self-Compassion ( 8 × 2-hr wkly sessions + retreat + daily practice)

Compassion meditation $(8 \times 2-\mathrm{hr}$ wkly sessions + daily taped practice)
Faces visualization exercise SS

Health discussion group (SS no homework)

Concentration meditation SS

Waitlist

Cognitive reappraisal SS

(A) Mindfulness SS (B)

Waitlist

Waitlist

(A) Mindfulness SS (B)

Improvisational theater class SS (C) No intervention

** Main study. Abbreviations: hr: hour; LKM: loving-kindness meditation; min: minute; NR: Number of participants randomized; SD: standard deviation; wk: week; SS: similar scheme. 
Figures

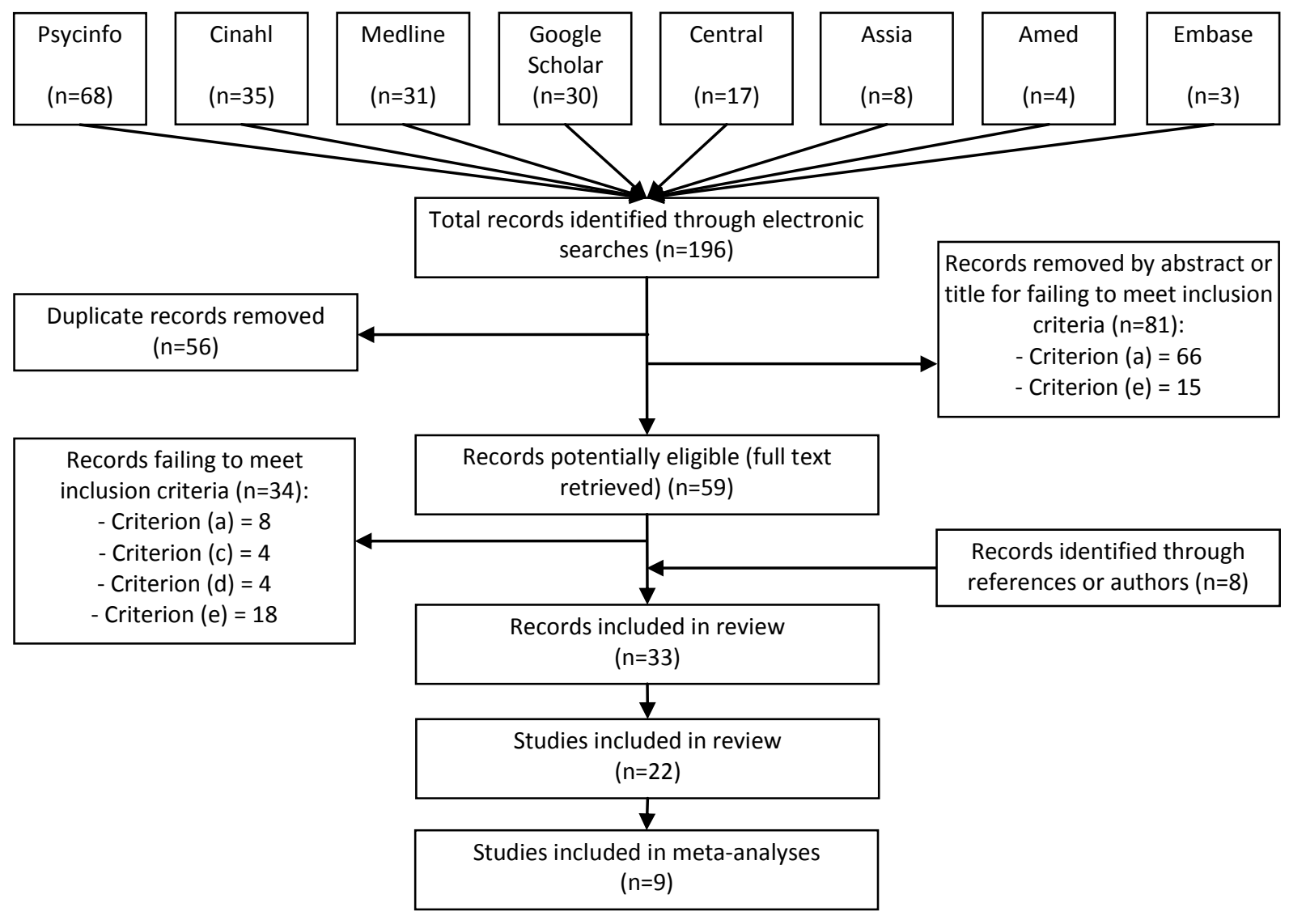

Figure 1. Study selection flow chart. Criteria were assessed in the following order: (a), (e),

(d), (c), (b). See text for criteria coding. 


\section{References}

Aknin, L. B., Dunn, E. W., \& Norton, M. I. (2012). Happiness runs in a circular motion: Evidence for a positive feedback loop between prosocial spending and happiness. Journal of Happiness Studies, 13(2), 347-355.

Barnhofer, T., Chittka, T., Nightingale, H., Visser, C., \& Crane, C. (2010). State effects of two forms of meditation on prefrontal EEG asymmetry in previously depressed individuals. Mindfulness, 1(1), 21-27.

Boellinghaus, I., Jones, F. W., \& Hutton, J. (2012). The role of mindfulness and loving-kindness meditation in cultivating self-compassion and other-focused concern in health care professionals. Mindfulness. Advance online publication. doi:10.1007/s12671012-0158-6

Boellinghaus, I. A. (2011). Cultivating compassion in psychological therapists: The potential of loving-kindness meditation. (Doctoral thesis, Canterbury Christ Church University). Retrieved from http://create.canterbury.ac.uk/10267/

Brand, S., Holsboer-Trachsler, E., Naranjo, J. R., \& Schmidt, S. (2012). Influence of mindfulness practice on cortisol and sleep in long-term and short-term meditators. Neuropsychobiology, 65(3), 109-118.

Brewer, J. A., Worhunsky, P. D., Gray, J. R., Tang, Y.-Y., Weber, J., \& Kober, H. (2011). Meditation experience is associated with differences in default mode network activity and connectivity. Proceedings of the National Academy of Sciences of the United States of America, 108(50), $20254-20259$.

Carson, J. W. (2006). Loving-kindness meditation findings not related to baseline differences. Journal of Holistic Nursing, 24(1), 5-6. 
Carson, J. W., Keefe, F. J., Lynch, T. R., Carson, K. M., Goli, V., Fras, A. M., \& Thorp, S. R. (2005). Loving-kindness meditation for chronic low back pain: Results from a pilot trial. Journal of Holistic Nursing, 23(3), 287-304.

Cohen, J. (1988). Statistical power analysis for the behavioral sciences (2nd ed.). Hillsdale, NJ: Erlbaum.

Cohen, J. (1992). A power primer. Psychological Bulletin, 112(1), 155-159.

Cohn, M. A. (2008). Positive emotions: Short-term mechanisms, long-term outcomes, and mediating processes. Dissertation Abstracts International: Section B: The Sciences and Engineering, 69(9-B), 5828.

Cohn, M. A., \& Fredrickson, B. L. (2010). In search of durable positive psychology interventions: Predictors and consequences of long-term positive behavior change. The Journal of Positive Psychology, 5(5), 355-366.

Condon, P., Desbordes, G., Miller, W., \& DeSteno, D. (2013). Meditation increases compassionate responses to suffering. Psychological Science, 24(10), 2125-2127.

Corcoran, C. C. (2007). A grounded theory exploration of lovingkindness meditation: Practitioner experience, reports of effects, and clinical relevance. 3268621 Psy.D., The Wright Institute, Ann Arbor. Retrieved from http://search.proquest.com/docview/304807371 accountid=27804 ProQuest Dissertations \& Theses Full Text database.

Crane, C., Jandric, D., Barnhofer, T., \& Williams, J. M. (2010). Dispositional mindfulness, meditation, and conditional goal setting. Mindfulness, 1(4), 204-214.

Crane, C., Jandric, D., Barnhofer, T., \& Williams, J. M. (2011). Dispositional mindfulness, meditation, and conditional goal setting: Erratum. Mindfulness, 2(2), 142.

Davidson, R. J., \& McEwen, B. S. (2012). Social influences on neuroplasticity: Stress and interventions to promote well-being. Nature Neuroscience, 15(5), 689-695. 
Desbordes, G., Negi, L. T., Pace, T. W., Wallace, B. A., Raison, C. L., \& Schwartz, E. L. (2012). Effects of mindful-attention and compassion meditation training on amygdala response to emotional stimuli in an ordinary, non-meditative state. Frontiers in Human Neuroscience, 6, 292.

Desbordes, G., Negi, L. T., Raison, C. L., \& Schwartz, E. L. (2012, June). Longitudinal decrease in amygdala response to emotional stimuli after eight-week meditation training. Poster presented at the 18th Annual Meeting of the Organization for Human Brain Mapping, Beijing, China. Poster retrieved from https://ww4.aievolution.com/hbm1201/index.cfm?do=abs.viewAbs\&abs=5336

Dunn, E. W., Aknin, L. B., \& Norton, M. I. (2008). Spending money on others promotes happiness. Science, 319(5870), 1687-1688.

Feldman, G., Greeson, J., \& Senville, J. (2010). Differential effects of mindful breathing, progressive muscle relaxation, and loving-kindness meditation on decentering and negative reactions to repetitive thoughts. Behaviour Research and Therapy, 48(10), 10021011.

Fredrickson, B. L., Cohn, M. A., Coffey, K. A., Pek, J., \& Finkel, S. M. (2008). Open hearts build lives: Positive emotions, induced through loving-kindness meditation, build consequential personal resources. Journal of Personality and Social Psychology, 95(5), 10451062.

Galante, J., Galante, I., Bekkers, M.-J., \& Gallacher, J. (2012). Effect of kindnessbased meditation on health and wellbeing. International prospective register of systematic reviews PROSPERO. (Registration number CRD42012003048). Available at http://www.crd.york.ac.uk/PROSPERO/display_record.asp?ID=CRD42012003048 
Galante, J., Iribarren, S. J., \& Pearce, P. F. (2012). Effects of mindfulness-based cognitive therapy on mental disorders: A systematic review and meta-analysis of randomised controlled trials. Journal of Research in Nursing, 18(2), 133-155.

Hedges, L. V., \& Olkin, I. (1985). Statistical methods for meta-analysis. New York, NY: Academic Press.

Higgins, J. P., Thompson, S. G., Deeks, J. J., \& Altman, D. G. (2003). Measuring inconsistency in meta-analyses. BMJ, 327(7414), 557.

Higgins, J. P. T., Altman, D. G., Gotzsche, P. C., Juni, P., Moher, D., Oxman, A. D., . . . Sterne, J. A. C. (2011). The Cochrane Collaboration's tool for assessing risk of bias in randomised trials. $B M J, 343(2), \mathrm{d} 5928-\mathrm{d} 5928$.

Higgins, J. P. T., \& Green, S. (Eds.). (2011). Cochrane handbook for systematic reviews of interventions. Chichester: John Wiley and Sons.

Hofmann, S. G., Grossman, P., \& Hinton, D. E. (2011). Loving-kindness and compassion meditation: Potential for psychological interventions. Clinical Psychology Review, 31, $1126-1132$.

Humphrey, C. W. (1999). A stress management intervention with forgiveness as the goal. Dissertation Abstracts International: Section B: The Sciences and Engineering(4-B), 1855.

Hunsinger, M., Livingston, R., \& Isbell, L. (2013). The impact of loving-kindness meditation on affective learning and cognitive control. Mindfulness, 4(3), 275 - 280.

Hutcherson, C. A., Seppala, E. M., \& Gross, J. J. (2008). Loving-kindness meditation increases social connectedness. Emotion, 8(5), 720-724.

Irwin, R. S. (2007). Clinical trial registration promotes patient protection and benefit, advances the trust of everyone, and is required. CHEST Journal, 131(3), 639-641. 
Jazaieri, H., Jinpa, G. T., McGonigal, K., Rosenberg, E. L., Finkelstein, J., SimonThomas, E., . . . Goldin, P. R. (2012). Enhancing compassion: A randomized controlled trial of a compassion cultivation training program. Journal of Happiness Studies. doi:10.1007/s10902-012-9373-z

Johnson, D. P., Penn, D. L., Fredrickson, B. L., Kring, A. M., Meyer, P. S., Catalino, L. I., \& Brantley, M. (2011). A pilot study of loving-kindness meditation for the negative symptoms of schizophrenia. Schizophrenia Research, 129(2-3), 137-140.

Kaliman, P., Álvarez-López, M. J., Cosín-Tomás, M., Rosenkranz, M. A., Lutz, A., \& Davidson, R. J. (2014). Rapid changes in histone deacetylases and inflammatory gene expression in expert meditators. Psychoneuroendocrinology, 40, 96-107.

Kelly, A. C. (2012). Training in self-compassion: Reducing distress and facilitating behaviour change. Dissertation Abstracts International: Section B: The Sciences and Engineering, 72(7-B), 4322.

Kendrick, T., \& Peveler, R. (2010). Guidelines for the management of depression: NICE work? . British Journal of Psychiatry, 197(5), 345-347.

Kenneth, F. S., Douglas, G. A., \& David, M. (2010). Consort 2010 statement: Updated guidelines for reporting parallel group randomised trials. $B M J, 340, \mathrm{c} 332$.

Kjaergard, L. L., Villumsen, J., \& Gluud, C. (2001). Reported methodologic quality and discrepancies between large and small randomized trials in meta-analyses. Annals of Internal Medicine, 135(11), 982-989.

Kleinman, B. M. (2010). Differential effects of meditation on relationship quality. Dissertation Abstracts International: Section B: The Sciences and Engineering, 72(1-B), 539.

Kok, B. E., Waugh, C. E., \& Fredrickson, B. L. (2013). Meditation and health: The search for mechanisms of action. Social and Personality Psychology Compass, 7(1), 27-39. 
Koopmann-Holm, B., Sze, J., Ochs, C., \& Tsai, J. L. (2013). Buddhist-inspired meditation increases the value of calm. Emotion, 13(3), 497-505.

Kristeller, J. L., \& Johnson, T. (2005). Cultivating loving kindness: A two-stage model of the effects of meditation on empathy, compassion, and altruism. Zygon, 40(2), 391-408.

Law, R. W. (2011). An analogue study of loving-kindness meditation as a buffer against social stress. Dissertation Abstracts International: Section B: The Sciences and Engineering, 72(7-B), 4365.

Lee, T. M., Leung, M. K., Hou, W. K., Tang, J. C., Yin, J., So, K. F., . . Chan, C. C. (2012). Distinct neural activity associated with focused-attention meditation and lovingkindness meditation. PLoS One, 7(8), e40054.

Leiberg, S., Klimecki, O., \& Singer, T. (2011). Short-term compassion training increases prosocial behavior in a newly developed prosocial game. PLoS One, 6(3).

Leppma, M. (2011). The effect of loving-kindness meditation on empathy, perceived social support, and problem-solving appraisal in counseling students. (Doctoral thesis, University of Central Florida). Retrieved from http://etd.fcla.edu/CF/CFE0003656/Leppma_Monica_201105_PhD.pdf

Lincoln, T. M., Hohenhaus, F., \& Hartmann, M. (2012). Can paranoid thoughts be reduced by targeting negative emotions and self-esteem? An experimental investigation of a brief compassion-focused intervention. Cognitive Therapy and Research. Advance online publication. doi:10.1007/s10608-012-9470-7

Lipizzi, E. (2011). Effect of compassion meditation and amount of exercise on body image in college freshmen. (Master's thesis, Emory University). Retrieved from http://pid.emory.edu/ark:/25593/943zr 
Livingston, R. W., \& Drwecki, B. B. (2007). Why are some individuals not racially biased? Susceptibility to affective conditioning predicts nonprejudice toward blacks. Psychological Science, 18(9), 816-823.

Lutz, A., Greischar, L. L., Perlman, D. M., \& Davidson, R. J. (2009). Bold signal in insula is differentially related to cardiac function during compassion meditation in experts vs. Novices. Neuroimage, 47(3), 1038-1046.

Macbeth, A., \& Gumley, A. (2012). Exploring compassion: A meta-analysis of the association between self-compassion and psychopathology. Clinical Psychology Review, $32(6), 545-552$.

Mascaro, J. S. (2011). A longitudinal investigation of empathic behavior and neural activity and their modulation by compassion meditation. Dissertation Abstracts International Section A: Humanities and Social Sciences, 72(12-A), 4629.

Mascaro, J. S., Rilling, J. K., Negi, L. T., \& Raison, C. L. (2013a). Compassion meditation enhances empathic accuracy and related neural activity. Soc Cogn Affect Neurosci, $8(1), 48-55$.

Mascaro, J. S., Rilling, J. K., Negi, L. T., \& Raison, C. L. (2013b). Pre-existing brain function predicts subsequent practice of mindfulness and compassion meditation. Neuroimage, 69, 35-42.

May, C. J., Weyker, J. R., Spengel, S. K., Finkler, L. J., \& Hendrix, S. E. (2012). Tracking longitudinal changes in affect and mindfulness caused by concentration and lovingkindness meditation with hierarchical linear modeling. Mindfulness. Advance online publication. doi:10.1007/s12671-012-0172-8

May, M. (2005). The effects of a self-acceptance training emphasizing compassion and mindfulness skills with inner experiences. Dissertation Abstracts International: Section B: The Sciences and Engineering, 66(1-B), 565. 
McGillicuddy, M., Dalton, L., Chakoian, K., Swanson, K., \& Feldman, G. (2010). The effect of personality traits on changes in positive affect and compassion following metta meditation, mindfulness meditation, and progressive muscle relaxation. Poster presented at the Simmons College, Boston, MA. Poster retrieved from author.

Neff, K. D., \& Germer, C. K. (2013). A pilot study and randomized controlled trial of the mindful self-compassion program. Journal of Clinical Psychology, 69(1), 28-44.

Neff, K. D., \& Pommier, E. (2012). The relationship between self-compassion and other-focused concern among college undergraduates, community adults, and practicing meditators. Self and Identity, 12(2), 160-176.

Ospina, M. B., Bond, K., Karkhaneh, M., Tjosvold, L., Vandermeer, B., Liang, Y., . . . Klassen, T. P. (2007). Meditation practices for health: State of the research. Edmonton, Alberta, Canada: University of Alberta Evidence-based Practice Center.

Ozawa-de Silva, B., Dodson-Lavelle, B., Raison, C. L., \& Negi, L. T. (2012). Compassion and ethics: Scientific and practical approaches to the cultivation of compassion as a foundation for ethical subjectivity and well-being. Journal of Healthcare, Science \& the Humanities, 2(1), 145-164.

Pace, T. W., Negi, L. T., Adame, D. D., Cole, S. P., Sivilli, T. I., Brown, T. D., . . . Raison, C. L. (2009). Effect of compassion meditation on neuroendocrine, innate immune and behavioral responses to psychosocial stress. Psychoneuroendocrinology, 34(1), 87-98.

Pace, T. W., Negi, L. T., Dodson-Lavelle, B., Ozawa-de Silva, B., Reddy, S. D., Cole, S. P., . . Raison, C. L. (2013). Engagement with cognitively-based compassion training is associated with reduced salivary C-reactive protein from before to after training in foster care program adolescents. Psychoneuroendocrinology, 38(2), 294-299.

Pocock, S. J. (1983). Clinical trials: A practical approach: Wiley. 
Pryor, V. K. (2011). Mindfulness and lovingkindness meditation: A comparative analysis. (Doctoral thesis, California Institute of Integral Studies). Retrieved from http://sunzi.lib.hku.hk/ER/detail/hkul/4812994

Reddy, S. D., Negi, L. T., Dodson-Lavelle, B., Ozawa-de Silva, B., Pace, T. W., Cole, S. P., . . Craighead, L. W. (2013). Cognitive-based compassion training: A promising prevention strategy for at-risk adolescents. Journal of Child and Family Studies, 22(2), 219 230.

Rosenberg, R. S., Baughman, S. L., \& Bailenson, J. N. (2013). Virtual superheroes: Using superpowers in virtual reality to encourage prosocial behavior. PLoS One, 8(1), e55003.

Salzberg, S. (1995). Loving-kindness: The revolutionary art of happiness. Boston: Shambala Publications.

Schulz, K. F. (1995). Subverting randomization in controlled trials. JAMA, 274(18), $1456-1458$.

Sedlmeier, P., Eberth, J., Schwarz, M., Zimmermann, D., Haarig, F., Jaeger, S., \& Kunze, S. (2012). The psychological effects of meditation: A meta-analysis. Psychological Bulletin, 138(6), $1139-1171$.

Standard, S. (2004). Effects of a forgiveness intervention on salivary cortisol, DHEA, and psychological variables. Dissertation Abstracts International: Section B: The Sciences and Engineering, 65(4-B), 2114.

Switzer, G. E., Simmons, R. G., Dew, M. A., Regalski, J. M., \& Wang, C.-H. (1995). The effect of a school-based helper program on adolescent self-image, attitudes, and behavior. The Journal of Early Adolescence, 15(4), 429-455. 
Templeton, J. L. (2007). Expanding circle morality: Believing that all life matters. Dissertation Abstracts International: Section B: The Sciences and Engineering, 68(2-B), 1342.

Thoits, P. A., \& Hewitt, L. N. (2001). Volunteer work and well-being. Journal of Health and Social Behavior, 42(2), 115-131.

Tonelli, M. E. W., Amy B. (2012). Meditation-based treatment yielding immediate relief for meditation-naïve migraineurs. Pain Management Nursing. Advance online publication. doi:10.1016/j.pmn.2012.04.002

Tsai, J. L. (2007). Ideal affect: Cultural causes and behavioral consequences. Perspectives on Psychological Science, 2(3), 242-259.

Vale, C. L., Tierney, J. F., \& Burdett, S. (2013). Can trial quality be reliably assessed from published reports of cancer trials: Evaluation of risk of bias assessments in systematic reviews. BMJ, 346(1), f1798-f1798.

Walker, M. J. (2006). The effects of nurses' practicing of the HeartTouch technique on perceived stress, spiritual well-being, and hardiness. Journal of Holistic Nursing, 24(3), 164175.

Wallmark, E., Safarzadeh, K., Daukantaitè, D., \& Maddux, R. E. (2013). Promoting altruism through meditation: An 8-week randomized controlled pilot study. Mindfulness, 4(3), $223-234$.

Walsh, R., \& Shapiro, S. (2006). The meeting of meditative disciplines and western psychology: A mutually enriching dialogue. American Psychologist, 61(3), 227-239.

Weibel, D. T. (2007 ). A loving-kindness intervention: Boosting compassion for self and others. Dissertation Abstracts International: Section B. Sciences and Engineering, $68(12), 8418$. 
Weng, H. Y., Fox, A. S., Shackman, A. J., Stodola, D. E., Caldwell, J. Z. K., Olson, M. C., .. . Davidson, R. J. (2013). Compassion training alters altruism and neural responses to suffering. Psychological Science, 24(7), 1171-1180.

Weng, H. Y., Lewis-Peacock, J., Stodola, D. E., \& J.Davidson, R. (2012, March). Multi-voxel pattern analysis of brain states after compassion training predicts charitable donations. Paper presented at the Annual Meeting of the Cognitive Neuroscience Society. Paper retrieved from http://www.princeton.edu/ jalewpea/abstracts/Weng_CNS2012_LongAbstract.pdf Williams, A.-L., Selwyn, P. A., Liberti, L., Molde, S., Njike, V. Y., McCorkle, R., . . . Katz, D. L. (2005). A randomized controlled trial of meditation and massage effects on quality of life in people with late-stage disease: A pilot study. Journal of Palliative Medicine, $8(5), 939-952$.

Williams, A.-L., Selwyn, P. A., McCorkle, R., Molde, S., Liberti, L., \& Katz, D. L. (2005). Application of community-based participatory research methods to a study of complementary medicine interventions at end of life. Complementary Health Practice Review, 10(2), 91-104.

Williams, J. M. G., \& Kabat-Zinn, J. (2011). Mindfulness: Diverse perspectives on its meaning, origins, and multiple applications at the intersection of science and dharma. Contemporary Buddhism, 12(1), 1-18.

Wong, G. (2011). Live to love as a way to love your living: Cultivating compassion by loving-kindness meditation. Dissertation Abstracts International: Section B: The Sciences and Engineering, 72(6-B), 3751. 